\title{
COVID-19-related anxiety in phenylketonuria patients
}

\author{
Halil Tuna Akar ${ }^{1 \oplus}$, Yamaç Karaboncuk ${ }^{2 \oplus}$, K1smet Çı1k1 ${ }^{1 \oplus}$, Ayça Burcu Kahraman ${ }^{1 \oplus,}$

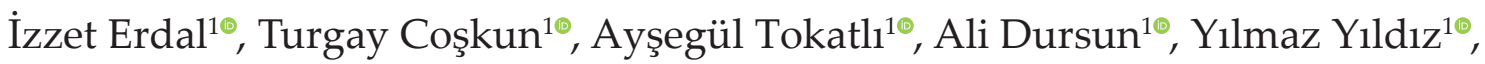 \\ H. Serap Sivri ${ }^{1 \odot}$ \\ ${ }^{1}$ Department of Pediatric Metabolism and Nutrition Unit, Hacettepe University Faculty of Medicine, Ankara; ${ }^{2}$ Ferhunde Öktem Mental \\ Health Center, Ankara, Turkey.
}

\begin{abstract}
Background. Phenylketonuria (PKU) is an inherited disorder of amino acid metabolism, the treatment of which often requires a special diet to prevent adverse neuropsychiatric outcomes. In the COVID-19 pandemic, which has had a substantial effect on the whole world since the beginning of 2020, PKU patients represent a vulnerable population because they may be dependent on special nutritional products, have limited access to routine care and display increased levels of anxiety.

Methods. For this reason, an online questionnaire assessing the anxiety levels and various personal opinions and practices regarding the pandemic was sent to the PKU patients managed at our clinic, who were 12 years of age or older. Ninety-eight patients responded to the questionnaire. Median age of the participants was 19 years.

Results. Most patients were compliant with the hygiene and social distancing recommendations regarding the spread of COVID-19. Of the patients, $61.2 \%$ felt more anxious since the pandemic. The most common concern was the possibility of not being able to obtain special nutritional products (58.2\%). Anxiety level was significantly higher in females.

Conclusions. These data suggest that food security is an important issue of concern in PKU patients. In line with the changing world after the pandemic, different strategies should be considered in the management of patients with inborn errors of metabolism, including PKU.
\end{abstract}

Key words: COVID-19, phenylketonuria, anxiety.

Phenylketonuria (PKU) is an inherited disorder of the breakdown pathyway of the amino acid phenylalanine. ${ }^{1}$ The resulting accumulation of phenylalanine causes intellectual disability and many other neuropsychiatric symptoms. ${ }^{2}$ Treatment must be initiated soon after birth and maintained lifelong, usually utilizing a phenylalanine-restricted diet to keep the blood phenylalanine level within a target range. ${ }^{3}$ Turkey has the highest incidence of PKU, at least partly due to the high rate of consanguinity. The newborn PKU screening program in Turkey, initiated by our department as a pilot study in

$凶$ H. Serap Sivri

ssivri@hacettepe.edu.tr

Received 8th March 2021, revised 31st March 2021, accepted 2nd April 2021.
1986, became a national screening program in $2006^{5-7}$

It is widely observed that adherence to dietary treatment is very good in childhood, but decreases thereafter, especially after adolescence, with phenylalanine levels exceeding the target levels. In fact, 31.1\% of the PKU patients in our clinic are poorly compliant to their dietary treatment. ${ }^{7-9}$ The diet is extremely challenging for the patients and their families, and often creates significant psychosocial and financial problems. ${ }^{10-13}$ Patients have difficulties in maintaining their diet at school and work, and experience anxiety and low self-esteem. ${ }^{14,15}$ Patients with PKU have a higher risk of psychiatric illness and cognitive impairment, even if they are treated early and 
effectively. ${ }^{16}$ Prevalence of neuropsychiatric symptoms such as carelessness, hyperactivity, depression and anxiety in PKU are above the general population estimates. Neuropsychiatric symptoms and executive dysfunction have been demonstrated to correlate with phenylalanine levels. ${ }^{17}$

COVID-19, the disease caused by SARS-CoV-2 was declared a pandemic by the World Health Organization on March 11, 2020. As of March 30, 2021, 3,277,880 confirmed cases and 31,385 deaths have been reported in our country. The elderly seem to develop more serious diseases and hypertension, cardiopulmonary diseases, cancer and diabetes are additional risk factors. ${ }^{18-20}$ In order to prevent the spread, staying at home and social isolation is encouraged, social activities have been canceled or postponed, and commercial activities were temporarily suspended or restricted in many countries. ${ }^{21}$ It is not surprising that such devastating alterations to social and economic life have had significant psychological impact on people all over the world. For example, in a general population study on the COVID-19 pandemic in India, the prevalence of anxiety and depression has been shown to increase. ${ }^{22}$ In the United Kingdom, pandemic-related anxiety, depression and trauma were shown to be associated with an underlying disease..$^{22}$ There are not many studies on how patients with rare diseases are affected by this pandemic. However, in a study conducted in Italy in April 2020, 49\% of patients receiving enzyme replacement therapy were reported to have pandemic-related disruptions in their treatment. ${ }^{23}$ National initiatives such as the French Rare Diseases Health Care Network for Neuromuscular Diseaeses (FILNEMUS) have sought to draw a path for how to track and manage patients with rare diseases. ${ }^{24}$ Similarly, patients with PKU may be affected by humanitarian, social and economic fluctuations due to their special needs. From this point of view, one may wonder how patients with PKU, a rare disease that may predispose them to neuropsychiatric findings such as anxiety, are coping with this pandemic. Therefore, we aimed to evaluate how they were affected by the COVID-19 pandemic, and assess their anxiety levels.

\section{Material and Methods}

This cross-sectional, observational study was carried out at the Pediatric Metabolism Unit of Hacettepe University İhsan Doğramac1 Children's Hospital, which is one of the largest metabolic centers in the region, and follows patients from all around Turkey, predominantly from Central Anatolia. Classical PKU patients 12 years of age and older who were actively followed in our clinic (came to at least one routine outpatient follow-up visit within the past year) were included in the study. In order to adhere to the social distancing efforts, patients in our center were contacted via telephone or social media, and questionnaire forms were delivered via Google Forms to the eligible patients followed at our center, and data was collected from the forms filled and submitted back by the patients anonymously. Written informed consent was obtained from the patients before participating in the online study.

As there were no validated self-report anxiety scales developed in relation to the COVID-19 pandemic, we sought to adapt a validated tool to the task at hand in order to formulate a questionnaire. The commonly used Beck Anxiety Scale consists of 21 questions and is fit for face-to-face application. ${ }^{25}$ Since faceto-face interviews were not applicable in the pandemic conditions, the scale needed to be condensed and simplified, so that it could be well understodd by an average older PKU patient with short attention span and possibly mildly impaired executive functions. The questionnaire was developed by physicians specialisng in metabolic disorders and clinical psychologists with years of experience with PKU patients. In summary, the questionnaire included structured questions adapted from Beck Anxiety Scale, encompassing demographic data, medical information, and self-reported 
anxiety, using short text answers, multiple choice and open-ended questions. Except for questions that inquired about demographic data, all questions were explicitly worded to inquire thoughts, feelings and practices in the last 15 days. The online questionnaire was sent out on 31 March 2020, and data collection was terminated on 1 June 2020.

The data obtained in the study were evaluated with SPSS (Statistical Package for the Social Sciences) version 21. Descriptive statistics, categorical variables were shown with numbers and percentages, and numerical variables with mean, standard deviation, median, range and interquartile range (IQR). KolmogorovSmirnov Test was used to assess normality of distributions. Mann Whitney U and Kruskal Wallis tests were used in comparing two and more independent groups, respectively. Chisquare and Fisher exact tests were used in the analysis of categorical variables. Spearman correlation test was used in the correlation analysis. Instances where the type- 1 error level is below $5 \%(p<0.05)$ were considered statistically significant. Hacettepe University Ethics Board for Non-interventional Clinical Studies approved the study (Approval Date: 31 March 2020 Issue: 2020/07-20).

\section{Results}

The questionnaire forms were sent out to 347 patients, 98 of whom $(28.2 \%$ of all eligible patients) participated in the study by returning the filled out forms. The demographic information of the patients is summarized in Table I. Of the patients, $50 \%(n=49)$ were female. The median age of the participants was 19 years (range:12-51 years). A median of four people resided in the household ( $\mathrm{IQR}=2$ ). Fifteen patients had comorbidities (three had hypothyroidism, and one each had anxiety disorder, osteoporosis, heart failure, ulcerative colitis, hereditary fructose intolerance, epilepsy, attention deficit and hyperactivity disorder). Of the patients $86.6 \%$ were being treated with phenylalanine restricted diet. All 41 patients
Table I. Clinical and demographic data of the study group ( $\mathrm{N}=98)$.

\begin{tabular}{|c|c|c|}
\hline & $\mathrm{n}$ & $\%$ \\
\hline \multicolumn{3}{|l|}{ Gender } \\
\hline Male & 49 & 50 \\
\hline Female & 49 & 50 \\
\hline \multicolumn{3}{|l|}{ Civil status } \\
\hline Lives with spouse/partner & 21 & 21.4 \\
\hline Single & 74 & 75.4 \\
\hline Divorced & 3 & 3.1 \\
\hline \multicolumn{3}{|l|}{ Working status of patients } \\
\hline Working constantly & 28 & 28.6 \\
\hline Not working & 70 & 70.4 \\
\hline \multicolumn{3}{|l|}{ Modality of treatment } \\
\hline Phenylalanine restricted diet & 84 & 86.6 \\
\hline Other & 8 & 8.2 \\
\hline $\begin{array}{l}\text { Does not comply with diet / } \\
\text { treatment }\end{array}$ & 5 & 5.2 \\
\hline $\begin{array}{l}\text { Presence of additional chronic } \\
\text { disease }\end{array}$ & 15 & 15.3 \\
\hline \multicolumn{3}{|l|}{ Working status of mother } \\
\hline Working constantly & 15 & 15.3 \\
\hline Not working & 82 & 83.7 \\
\hline Not specified & 1 & 1 \\
\hline \multicolumn{3}{|l|}{ Working status of father } \\
\hline Working constantly & 71 & 72.4 \\
\hline Not working & 25 & 25.5 \\
\hline Not specified & 2 & 2 \\
\hline $\begin{array}{l}\text { Living with an individual over the } \\
\text { age of } 65\end{array}$ & 11 & 11.2 \\
\hline $\begin{array}{l}\text { Living with another patient with } \\
\text { phenylketonuria }\end{array}$ & 13 & 13.3 \\
\hline \multicolumn{3}{|l|}{$\begin{array}{l}\text { Media for social contact with } \\
\text { acquaintances during pandemic }\end{array}$} \\
\hline Face to face contact & 16 & 16.10 \\
\hline By phone & 52 & 53.10 \\
\hline By video call & 33 & 33.7 \\
\hline Internet based systems & 38 & 38.8 \\
\hline Via social media & 33 & 33.7 \\
\hline
\end{tabular}

Distribution of the sources from which patients received information during the COVID-19 pandemic

$\begin{array}{lcc}\text { Television broadcasts } & 80 & 81.6 \\ \text { Physician's opinion } & 17 & 17.3 \\ \text { Internet broadcasts } & 51 & 52 \\ \text { Family members } & 47 & 48 \\ \text { Friends } & 12 & 12.2 \\ \text { Other } & 3 & 3.10\end{array}$


under the age of 18 attended school. Among the remaining 57 patients older than 18 years, 25 $(43.8 \%)$ had a steady job.

Of the patients $76.5 \%(\mathrm{n}=75)$ stated that they had social contact with friends during the pandemic. Most of the patients (53.1\%) contacted their friends over the phone.

Patients were asked if their knowledge level about the COVID-19 pandemic was sufficient. Of the patients $67.3 \%(\mathrm{n}=66)$ stated that they had sufficient information about the pandemic. The patients were also asked what their sources of information were. The majority of patients $(81.6 \%)$ stated that they learned about the pandemic via television, followed by internet broadcasts $(52 \%)$.

The self-reported anxiety levels of the patients are given in Table II. Of the participants , 61.2\% reported that they felt more anxious since the pandemic. The biggest concern of the patients was the possibility of not being able to obtain special nutrition products $(58.2 \%)$. Of the patients $79.6 \%(\mathrm{n}=78)$ described at least one sign of anxiety. Of the participants , $21.4 \%$ stated that they had difficulty in dealing with anxiety. Female participants significantly more commonly reported that they had difficulty coping with anxiety since the onset of the pandemic ( $37.2 \%$ vs. $10.4 \%$, $\mathrm{p}=0.010)$, felt sad or unhappy $(59.6 \%$ vs. $36.2 \%$, $\mathrm{p}=0.023)$, worthless $(19.1 \%$ vs. $4.3 \%$, $\mathrm{p}=0.025)$, scared without reason (75.6\% vs. $46.9 \%$, $\mathrm{p}=0.005)$, and had palpitations unrelated to physical activity ( $21.7 \%$ vs. $6.1 \%$, $\mathrm{p}=0.027$ ).

The precautionary measures taken by patients against the COVID-19 pandemic were also inquired. The patients' responses are summarized in Table II. Patients mostly paid attention to hygiene recommendations (66.3\%). Of the participants $55.1 \%$ fully complied with the rule of staying at home.

The patients were asked to give their anxiety levels a score from 1 to 5 . Self-reported anxiety levels and age, gender, source of information, level of knowledge, and treatment modality were compared (Table III). No statistically significant results were obtained, except for gender. Anxiety level was higher in females than in males. Age was not significantly correlated with anxiety levels (Spearman's correlation coefficient $\mathrm{Q}=0.085, \mathrm{p}=0.413$ ). No statistically significant relationship was found between the source of the information about pandemic and the level of anxiety.

Before the participants participated in the survey, their consent was obtained online.

\section{Discussion}

The COVID-19 pandemic affected the world as well as our country, and our patients. We wanted to investigate the concerns of a vulnerable and rare patient population in this difficult process and the factors that may influence this anxiety, using a web-based study, befitting the new norms of communication during this unprecedented pandemic.

The time frame of this study coincides with the initial stages of the pandemic response in Turkey. On 11 March 2020, the first cases of SARS-CoV-2 detected in Turkey was announced by the Ministry of Health. The first COVID-19related death occurred on March 15, 2020. The Ministry of Health announced on April 1, 2020 that coronavirus cases were seen in all regions of the country. As of March 13, 2020, restrictions were gradually imposed on foreign entries and exits. As of March 16, 2020, restrictions have been placed on social-cultural-religious meetings within the country. On April 3, 2020, a curfew was imposed across the country for those born later than December 31, 1999, masks were imposed in public areas such as markets, and entrances and exits to 30 metropolitan cities were halted for 15 days. Curfews of different days and lengths were declared as of April 10, 2020. The easing of the initial restrictions did not ocur until June 1, 2020, which coincides with the end of data collection for this study. In other words, the data was collected at a time when the scientific information was premature, 
Table II. Anxiety level assesments of patients and evaluation of the measures taken by patients during COVID-19 pandemic.

\begin{tabular}{|c|c|c|}
\hline & $\mathrm{n}$ & $\%$ \\
\hline \multicolumn{3}{|l|}{ How did your anxiety change during the pandemic? } \\
\hline Decreased & 3 & 3.1 \\
\hline Did not change & 34 & 34.7 \\
\hline Increased & 60 & 61.2 \\
\hline \multicolumn{3}{|l|}{ What are your concerns about the pandemic? } \\
\hline I feel more at risk than the general population & 55 & 56.1 \\
\hline I think I am at risk of having problems accessing healthcare services & 41 & 41.8 \\
\hline I think I may have difficulties in accessing special nutrition products & 57 & 58.2 \\
\hline I think I may have difficulty in accessing medicinal products & 41 & 41.8 \\
\hline I think I'm more likely to get infected & 53 & 54.1 \\
\hline I think that if I get infected, I will be seriously ill & 49 & 50 \\
\hline I think one of my family members will get sick & 28 & 28.6 \\
\hline Other & 14 & 14.3 \\
\hline \multicolumn{3}{|l|}{ How was your last 15 days since the pandemic started? } \\
\hline Partially coped & 27 & 27.6 \\
\hline Neutral & 43 & 43.9 \\
\hline Difficult to deal with & 21 & 21.4 \\
\hline Not specified & 7 & 7.1 \\
\hline \multicolumn{3}{|l|}{ I felt unhappy and sad } \\
\hline Yes & 45 & 45.9 \\
\hline No & 49 & 50 \\
\hline Not specified & 4 & 4.1 \\
\hline \multicolumn{3}{|l|}{ I felt worthless } \\
\hline Yes & 11 & 11.2 \\
\hline No & 83 & 84.7 \\
\hline Not specified & 4 & 4.1 \\
\hline \multicolumn{3}{|l|}{ I had a hard time taking the first step to do a job } \\
\hline Yes & 27 & 27.6 \\
\hline No & 64 & 65.3 \\
\hline Not specified & 7 & 7.1 \\
\hline \multicolumn{3}{|l|}{ Sometimes I feel scared even though it doesn't have a logical explanation } \\
\hline Yes & 57 & 58.2 \\
\hline No & 37 & 37.8 \\
\hline Not specified & 4 & 4.1 \\
\hline \multicolumn{3}{|l|}{ I had difficulty breathing even though I did not do a physical activity } \\
\hline Yes & 9 & 9.2 \\
\hline No & 85 & 86.7 \\
\hline Not specified & 4 & 4.1 \\
\hline \multicolumn{3}{|l|}{ I felt my heart beating fast even though I was not doing any physical activity } \\
\hline Yes & 13 & 13.3 \\
\hline No & 82 & 83.7 \\
\hline Not specified & 3 & 3.1 \\
\hline
\end{tabular}


Table II. Continued.

\begin{tabular}{lcc}
\hline & $\mathrm{n}$ & $\%$ \\
\hline I feel that I am more sensitive & 13 & 13.3 \\
Yes & 82 & 83.7 \\
No & 3 & 3.1 \\
Not specified & & \\
I tend to overreact to events & 35 & 35.7 \\
Yes & 59 & 60.2 \\
No & 4 & 4.1 \\
Not specified & & \\
What would your score be if you scored 1 to 5 on the level of anxiety the pandemic created in & & \\
you? & & 9.2 \\
1-I'm not worried at all & 21 & 21.4 \\
2- I'm less concerned & 41 & 41.8 \\
3-I'm concerned & 22 & 22.4 \\
4-I'm very worried & 3 & 3.1 \\
5-I can't deal with my anxiety & & \\
Have you experienced an event or events today that caused your anxiety to increase? & 33 & 33.7 \\
Yes & 31 & 31.6 \\
No & 34 & 34.7 \\
Not specified & & \\
What COVID-19 precaution measures are you taking? & 65 & 66.3 \\
I pay attention to hygiene. & 59 & 60.2 \\
I try to follow social isolation rules. & 9 & 9.2 \\
I am trying to strengthen my immune system. & \multicolumn{2}{c}{. } \\
Do you follow the rule of staying at home? & 54 & 55.1 \\
I comply fully & 41 & 41.8 \\
I rarely go out (eg only for the market) & 2 & 2 \\
I don't follow the rule of staying at home & 1 & 1 \\
Not specified & & \\
\hline
\end{tabular}

daily news were concerned primarily with the pandemic and even the short-term future was full of uncertainties. The stressful time in which the study was conducted might have contributed to the high anxiety levels reported in the study questionnaire.

The majority of the participants reported at least some adherence to their diet, and many of them managed to maintain social contact with peers, mostly over the phone. Of participants $81.6 \%$ received information about the pandemic via television and $52 \%$ via the internet. Although new media platforms come to the fore, it is worthy to note that, at least in this patient population, television broadcasting still has a very important effect. Only $17.3 \%$ of the patients received information from a physician. This low rate may have resulted from the decrease in routine physician or hospital visits during the pandemic. It may be difficult to achieve the classical patient-physician relationship in the pandemic, when face-to-face interactions are avoided unless absolutely necessary. Telemedicine practices in many different disciplines were strongly discussed in the pandemic process. ${ }^{26-29}$ It is necessary to mention the critical role of social media and mass media in the acquisition of information in this process. However, this has some drawbacks. In a study 
Table III. Comparison of pandemic-related anxiety levels of patients in terms of gender, knowledge level, measures taken and treatment modalities.

\begin{tabular}{|c|c|c|c|c|c|c|}
\hline & \multicolumn{5}{|c|}{ COVID-19 self-reported anxiety state } & \multirow{2}{*}{$\mathrm{p}$} \\
\hline & $1^{+}$ & $2^{+}$ & $3^{+}$ & $4^{+}$ & $5^{+}$ & \\
\hline Gender & & & & & & $0.002^{*}$ \\
\hline Male & $6(12.5 \%)$ & $15(31.3 \%)$ & $20(41.7 \%)$ & $7(14.6 \%)$ & $0(0 \%)$ & \\
\hline Female & $3(6.3 \%)$ & $6(12.5 \%)$ & $21(43.8 \%)$ & $15(31.3 \%)$ & $3(6.3 \%)$ & \\
\hline Age & & & & & & 0.602 \\
\hline$<18$ years & $4(10 \%)$ & $8(20 \%)$ & $20(50 \%)$ & $8(20 \%)$ & $0(0 \%)$ & \\
\hline$\geq 18$ years & $5(9.1 \%)$ & $13(23.6 \%)$ & $21(38.2 \%)$ & $13(23.6 \%)$ & $3(5.5 \%)$ & \\
\hline Pandemic subjective knowledge level & & & & & & 0.0990 \\
\hline Enough & $6(9.1 \%)$ & $11(16.7 \%)$ & $35(53 \%)$ & $13(19.7 \%)$ & $1(1.5 \%)$ & \\
\hline Not enough & $3(10 \%)$ & $10(33.3 \%)$ & $6(20 \%)$ & $9(30 \%)$ & $2(6.7 \%)$ & \\
\hline Compliance with lockdown & & & & & & 0.487 \\
\hline Fully compliant & $8(14.8 \%)$ & $11(20.4 \%)$ & $21(38.9 \%)$ & $12(22.2 \%)$ & $2(3.7 \%)$ & \\
\hline Rarely goes out & $1(2.5 \%)$ & $9(22.5 \%)$ & $19(47.5 \%)$ & $10(25 \%)$ & $1(2.5 \%)$ & \\
\hline Non-compliant & $0(0 \%)$ & $1(50 \%)$ & $1(50 \%)$ & $0(0 \%)$ & $0(0 \%)$ & \\
\hline Measure taken & & & & & & 0.616 \\
\hline Paying attention to hygiene & $7(10.9 \%)$ & $16(25 \%)$ & $24(37.5 \%)$ & $14(21.9 \%)$ & $3(4.7 \%)$ & \\
\hline Following social isolation & $4(6.9 \%)$ & $14(24.1 \%)$ & $27(46.6 \%)$ & $13(22.4)$ & $0(0 \%)$ & \\
\hline Trying to strengthen immune system & $1(11.1 \%)$ & $2(22.2 \%)$ & $2(22.2 \%)$ & $4(44.4 \%)$ & $0(0 \%)$ & \\
\hline Treatment modality & & & & & & 0.769 \\
\hline Phenylalanine restricted diet & $8(9.5 \%)$ & $21(25 \%)$ & $34(40.5 \%)$ & $18(21.4 \%)$ & $3(3.6 \%)$ & \\
\hline Other & $0(0 \%)$ & $0(0 \%)$ & $6(75 \%)$ & $2(25 \%)$ & $0(0 \%)$ & \\
\hline Does not comply with diet / treatment & $1(25 \%)$ & $0(0 \%)$ & $1(25 \%)$ & $2(50 \%)$ & 0 & \\
\hline \multicolumn{7}{|l|}{$\begin{array}{l}\text { Source of information about COVID-19 } \\
\text { pandemic }\end{array}$} \\
\hline Television broadcasts & $6(7.6 \%)$ & $16(20.3 \%)$ & $34(43.0 \%)$ & $20(25.3 \%)$ & $3(3.8 \%)$ & 0.425 \\
\hline Physician's opinion & $1(5.9 \%)$ & $5(29.4 \%)$ & $9(52.9 \%)$ & $2(11.8 \%)$ & $0(0 \%)$ & 0.651 \\
\hline Internet broadcasts & $2(4 \%)$ & $11(22 \%)$ & $21(42 \%)$ & $15(30 \%)$ & $1(\% 2)$ & 0.198 \\
\hline Family members & $3(6.5 \%)$ & $11(23.9 \%)$ & $17(37 \%)$ & $14(30.4 \%)$ & $1(2.2 \%)$ & 0.406 \\
\hline Friends & $0(0 \%)$ & $5(41.7 \%)$ & $4(33.3 \%)$ & $3(25 \%)$ & $0(0 \%)$ & 0.425 \\
\hline $\begin{array}{l}\mathrm{p}<0.05 \\
\text { 1-I'm not worried at all } \\
\text { 2- I'm less concerned } \\
\text { 3-I'm concerned } \\
\text { 4-I'm very worried } \\
\text { 5-I can't deal with my anxiety }\end{array}$ & & & & & & \\
\hline
\end{tabular}

conducted in Turkey, Youtube videos related to the COVID-19 pandemic were examined. Video contents were audited and only $37.5 \%$ were found useful. Of those evaluated $15.8 \%$ of Turkish and $10.4 \%$ of English videos were found to have false/misleading information. ${ }^{30}$ It may be possible to use social and new media tools to our advantage to alleviate anxiety during an epidemic. It is important to use and produce accurate, reliable and reputable sources of information. $^{31,32}$

Of the patients in the study group $61.2 \%$ stated that their anxiety increased during the pandemic, $45.9 \%$ were unhappy and upset, $11.2 \%$ felt unworthy and $35.7 \%$ stated that they 
overreacted to events. It is noteworthy that these and similar symptoms of depression are present in the study group. In the COVID-19 pandemic, many health-care workers showed signs of anxiety and depression. ${ }^{33}$ Similarly, anxiety levels in the general population have also increased. ${ }^{15,22,34,35}$ However, such studies addressing patients with rare diseases have been lacking, which has motivated us to perform this study.

The most common concern of the patients $(58.2 \%)$ was the possibility of not being able to obtain special nutrition products. It is known that many people around the world stock food with the concern that they may not be able to find basic food items. ${ }^{36,37}$ It is not surprising that PKU patients experience a higher anxiety regarding access to food because they acquire their medical foods from pharmacies, or they already have financial or logistic difficulties in obtaining their special low-protein food products. ${ }^{38,39}$ This additional burden is unique to patients with PKU and with other rare inborn errors of metabolism requiring special diets. It is important to advocate for policies that ensure food and medicinal product security in this vulnerable patient population suffering from rare, orphan diseases. It is also concerning that Turkey is dependent on import of medical foods and drugs, especially in the rare diseases group. In particular, the possibility that the closure of the borders would disrupt the global logistics chain and/or cause a decrease in production capacities probably contributed to the anxiety of the participants.

In our study, pandemic-related anxiety levels were more common in females. This may be significant in terms of gender preference of anxiety symptoms in the general population. ${ }^{40}$ In the literature, it has been shown that clinical findings of anxiety appear during adolescence and early adulthood. ${ }^{41}$ However, when the distribution of anxiety levels in terms of age was examined in our study, no statistical difference was found. This may be related to the fact that the participants were all older than 12 years.
Our study has its limitations. Since the questionnaires were not completed via a faceto-face interview and the patients are asked to complete the questionnaire themselves, it is not known whether the patients understood the questions completely. In addition, the patients self-expressed their anxiety levels and knowledge levels. Performing face-to-face mental state examinations to assess anxiety more objectively was not feasible. As the filled questionnaires were returned anonymously, researchers were blinded to the identities of the participants, making it impossible to correlate the answers with clinical data.

Since the COVID-19 pandemic is a process full of unknowns, and was especially so in the initial stages, it cannot be denied that there were many questions raised in the inborn errors of metabolism patient community. We had the opportunity to observe this both during the study and while providing patient service. In the beginning, the questions mainly concerned whether they would be sick more easily than the society and what their prognosis would be if they were sick. So far, there has been no indication that people with PKU may be under higher risk of infection, or of more severe disease. The results of this study show that the level of COVID-19 pandemic-related anxiety was high in patients with PKU, and significantly higher in females. Food insecurity regarding medical and low-protein foods was a major concern, which was not an issue previously addressed in the literature. Our study suggests that different support strategies should be brought into the spotlight by taking into consideration the changing world and medical practices in the post-COVID-19 era. Especially, in new communication channels such as social media and the internet, it may be useful to open areas where health care providers can provide patients with reliable information, and share their concerns and problems. In addition, guaranteeing the supply chain of food and medicinal products in cooperation with the local authorities may reduce the anxiety levels. 
This may also applicable to other rare metabolic disorders requiring special diets. In this respect, monitoring of inborn errors of metabolism patients with telehealth applications should be discussed in the community. At this point, the contribution of patients, families and non-governmental organizations cannot be overemphasized.

\section{Acknowledgment}

We would like to thank our patients, their families, patient and family associations. Their support has always been with us.

\section{Ethical approval}

Hacettepe University Ethics Board for Noninterventional Clinical Studies approved the study (Approval Date: 31 March 2020 Issue: 2020 / 07-20).

\section{Author contribution}

The authors confirm contribution to the paper as follows: study conception and design: HTA, YK, $\mathrm{AD}, \mathrm{AT}, \mathrm{TC}$ SS; data collection: HTA, KÇ, ABK, IE; data analysis and interpretation: HTA, YK, YY, SS; drafting of manuscript: HTA, YK, YY; critical review of manuscript: $\mathrm{YY}, \mathrm{AD}, \mathrm{AT}, \mathrm{TC}$, SS. All authors approve and take responsibility for the final version of the manuscript.

\section{Source of funding}

The study did not received funding.

\section{Conflict of interest}

The authors declare no conflict of interest.

\section{REFERENCES}

1. Blau N, van Spronsen FJ, Levy HL. Phenylketonuria. Lancet 2010; 376: 1417-1427.

2. van Spronsen F, Huijbregts SC, Bosch AM, Leuzzi V. Cognitive, neurophysiological, neurological and psychosocial outcomes in early-treated PKUpatients: a start toward standardized outcome measurement across development. Mol Genet Metab 2011; 104(Suppl): S45-S51.

3. Ney DM, Gleason ST, van Calcar SC, et al. Nutritional management of PKU with glycomacropeptide from cheese whey. J Inherit Metab Dis 2009; 32: 32-39.

4. Özalp I, Coşkun T, Ceyhan M, et al. Incidence of phenylketonuria and hyperphenylalaninaemia in a sample of the Turkish newborn population. In: Addison GM, Harkness RA, Isherwood DM, Pollit RJ (eds). Practical Developments in Inherited Metabolic Disease: DNA Analysis, Phenylketonuria and Screening for Congenital Adrenal Hyperplasia. Dordrecht: Springer, 1986: 237-239.

5. Özalp I, Coşkun T, Tokatli A, et al. Neonatal PKU screening in Turkey: 7 years experience in a developing country. Screening 1995; 4: 139-147.

6. Tezel B, Dilli D, Bolat H, et al. The development and organization of newborn screening programs in Turkey. J Clin Lab Anal 2014; 28: 63-69.

7. Ozalp I, Coşkun T, Tokatli A, et al. Newborn PKU screening in Turkey: at present and organization for future. Turk J Pediatr 2001; 43: 97-101.

8. Yilmaz Ö. Fenilketonürili bireylerde diyet fenilalanin toleransının değerlendirilmesi. Ankara: Hacettepe Üniversitesi Sağlık Bilimleri Enstitüsü, 2017.

9. Abstracts presented at the 13th International Congress of Inborn Errors of Metabolism - ICIEM 2017. J Inborn Errors Metab Screen 2017; 5: 1-413.

10. Wang L, Zou H, Ye F, et al. Household financial burden of phenylketonuria and its impact on treatment in China: a cross-sectional study. J Inherit Metab Dis 2017; 40: 369-376.

11. Eijgelshoven I, Demirdas S, Smith TA, van Loon JM, Latour S, Bosch AM. The time consuming nature of phenylketonuria: a cross-sectional study investigating time burden and costs of phenylketonuria in the Netherlands. Mol Genet Metab 2013; 109: 237-242. 
12. Gramer G, Haege G, Glahn EM, Hoffmann GF, Lindner M, Burgard P. Living with an inborn error of metabolism detected by newborn screeningparents' perspectives on child development and impact on family life. J Inherit Metab Dis 2014; 37: 189-195.

13. MacDonald A, Smith TA, de Silva S, Alam V, van Loon JM. The personal burden for caregivers of children with phenylketonuria: a cross-sectional study investigating time burden and costs in the UK. Mol Genet Metab Rep 2016; 9: 1-5.

14. Ford S, O'Driscoll M, MacDonald A. Living with phenylketonuria: lessons from the PKU community. Mol Genet Metab Rep 2018; 17: 57-63.

15. Gunduz M, Arslan N, Unal O, Cakar S, Kuyum P, Bulbul SF. Depression and anxiety among parents of phenylketonuria children. Neurosciences (Riyadh) 2015; 20: 350-356.

16. Ashe K, Kelso W, Farrand S, et al. Psychiatric and cognitive aspects of phenylketonuria: the limitations of diet and promise of new treatments. Front Psychiatry 2019; 10: 561.

17. Bilder DA, Noel JK, Baker ER, et al. Systematic review and meta-analysis of neuropsychiatric symptoms and executive functioning in adults with phenylketonuria. Dev Neuropsychol 2016; 41: 245260.

18. Liu K, Chen Y, Lin R, Han K. Clinical features of COVID-19 in elderly patients: a comparison with young and middle-aged patients. J Infect 2020; 80: e14-e18.

19. Jordan RE, Adab P, Cheng K. Covid-19: risk factors for severe disease and death. Br Med J 2020; 368: m1 198.

20. Zhou F, Yu T, Du R, et al. Clinical course and risk factors for mortality of adult inpatients with COVID-19 in Wuhan, China: a retrospective cohort study. Lancet 2020; 395: 1054-1062.

21. Wilder-Smith A, Freedman D. Isolation, quarantine, social distancing and community containment: pivotal role for old-style public health measures in the novel coronavirus (2019-nCoV) outbreak. J Travel Med 2020; 27: taaa020.

22. Roy D, Tripathy S, Kar SK, Sharma N, Verma SK, Kaushal V. Study of knowledge, attitude, anxiety \& perceived mental healthcare need in Indian population during COVID-19 pandemic. Asian J Psychiatr 2020; 51: 102083.

23. Sechi A, Macor D, Valent S, et al. Impact of COVID-19 related healthcare crisis on treatments for patients with lysosomal storage disorders, the first Italian experience. Mol Genet Metab 2020; 130: 170-171.
24. Solé G, Salort-Campana E, Pereon Y, et al; FILNEMUS COVID-19 study group Guidance for the care of neuromuscular patients during the COVID-19 pandemic outbreak from the French Rare Health Care for Neuromuscular Diseases Network. Rev Neurol (Paris) 2020; 176: 507-515.

25. Julian LJ. Measures of anxiety: State-Trait Anxiety Inventory (STAI). Beck Anxiety Inventory (BAI), and Hospital Anxiety and Depression Scale-Anxiety (HADS-A) 2011; 63(Suppl 11): S467-S472.

26. Bini SA, Schilling PL, Patel SP, et al. Digital orthopaedics: a glimpse into the future in the midst of a pandemic. J Arthroplasty 2020; 35: S68-S73.

27. Chung CJ, Nazif TM, Wolbinski M, et al. Restructuring of structural heart disease practice during the Covid-19 pandemic. J Am Coll Cardiol 2020; 75: 2974-2983.

28. Schrag D, Hershman DL, Basch E. Oncology practice during the COVID-19 pandemic. JAMA 2020; 323: 2005-2006.

29. Vaccaro AR, Getz CL, Cohen BE, Cole BJ, Donnally CJ 3rd. Practice management during the COVID-19 pandemic. J Am Acad Orthop Surg 2020; 28: 464-470.

30. Atac O, Ozalp Y, Kurnaz R, Guler OM, Inamlik M, Hayran $\mathrm{O}$. YouTube as an information source during the Coronavirus disease (COVID-19) pandemic: evaluation of the Turkish and English content. medRxiv doi: https://doi.org/10.1101/2020.05.06.200 93468.

31. Wiederhold BK. Using social media to our advantage: alleviating anxiety during a pandemic. Cyberpsychol Behav Soc Netw 2020; 23: 197-198.

32. Rosenberg H, Syed S, Rezaie S. The Twitter pandemic: the critical role of Twitter in the dissemination of medical information and misinformation during the COVID-19 pandemic. CJEM 2020; 22: 418-421.

33. Pappa S, Ntella V, Giannakas T, Giannakoulis VG, Papoutsi E, Katsaounou P. Prevalence of depression, anxiety, and insomnia among healthcare workers during the COVID-19 pandemic: a systematic review and meta-analysis. Brain Behav Immun 2020; 88: 901-907.

34. Limcaoco RSG, Mateos EM, Fernandez JM, Roncero C. Anxiety, worry and perceived stress in the world due to the COVID-19 pandemic, March 2020. Preliminary results. medRxiv doi: https://doi.org/10. 1101/2020.04.03.20043992.

35. Zhang J, Lu H, Zeng $\mathrm{H}$, et al. The differential psychological distress of populations affected by the COVID-19 pandemic. Brain Behav Immun 2020; 87: 49-50. 
36. Nicola M, Alsafi Z, Sohrabi C, et al. The socioeconomic implications of the coronavirus pandemic (COVID-19): a review. Int J Surg 2020; 78: 185-193.

37. Manderson L, Levine S. COVID-19, risk, fear, and fall-out. Med Anthropol 2020; 39: 367-370.

38. Berry SA, Brown CS, Greene C, Camp KM, McDonough S, Bocchini JA Jr; Follow-up and Treatment (FUTR) Workgroup for the Advisory Committee on Heritable Disorders in Newborns and Children. Medical foods for inborn errors of metabolism: history, current status, and critical need. Pediatrics 2020; 145: e20192261.
39. Coakley KE, Porter-Bolton S, Salvatore ML, Blair RB, Singh RH. Food insecurity in females with phenylketonuria. JIMD Rep 2020; 53: 103-110.

40. Li SH, Graham BM. Why are women so vulnerable to anxiety, trauma-related and stress-related disorders? The potential role of sex hormones. Lancet Psychiatry 2017; 4: 73-82.

41. de Lijster JM, Dierckx B, Utens EM, et al. The age of onset of anxiety disorders: a meta-analysis. Can J Psychiatry 2017; 62: 237-246. 